DOI: $10.12731 / 2306-1561-2013-4-28$

\title{
DIAGNOSTICS OF DEVELOPMENT OF ORGANIZATIONAL AND MANAGERIAL COMPETENCIES OF THE ENGINEERS USING THE SELF-ORGANIZING KOHONEN MAPS
}

\begin{abstract}
Akhterov A.V., Lezina O.V., Shastina A.E.
Abstract

The goal of the development of organizational and managerial competencies engineers dictated by change of the content of engineering, to the requirements of the society to the modern engineer, socio-economic benchmarks, etc. To achieve the objectives of the developed complex of pedagogical conditions, contributing to the development of programs of improvement of professional skill. The paper considers modern neural network approach to the evaluation of the effectiveness of mastering engineers of the program of development of organizational and managerial competencies, based on application of self-organizing Kohonen maps.
\end{abstract}

Keywords: organizational and managerial competencies, engineer, training, performance evaluation, neural networks, self-organizing Kohonen maps.

\section{УДК 377.4}

\section{ДИАГНОСТИКА РАЗВИТИЯ ОРГАНИЗАЦИОННО-УПРАВЛЕНЧЕСКИХ КОМПЕТЕНЦИЙ ИНЖЕНЕРОВ С ПОМОЩЬЮ САМООРГАНИЗУЮЩИХСЯ КАРТ КОХОНЕНА}

\section{Ахтеров А.В., Лезина О.В., Шастина А.Е.}

\section{Аннотация}

Цель развития организационно-управленческих компетенций инженеров продиктована изменением содержания инженерной деятельности, требованиями общества к современному инженеру, социально-экономическими ориентирами и т.д. Для достижения иели разработан комплекс педагогических условий, способствующий освоению программ повышения квалификации. В статье рассматривается современный нейросетевой подход к оценке эффективности усвоение инженерами программы развития организационно-управленческих компетенций, основанный на применении самоорганизующихся карт Кохонена.

Ключевые слова: организационно-управленческие компетенции, инженер, повышение квалификации, оценка эффективности, нейронная сеть, самоорганизуюшиеся карты Кохонена. 
Организационно-управленческие компетенции (ОУК), наряду с базовыми (общепрофессиональными) и специализированными (профессионально-профильными), относятся к профессиональным компетенциям, и включают способность организовывать и планировать работу, извлекать и анализировать информацию из разных источников, применять полученные знания на практике, адаптироваться к новым ситуациям и т.д.

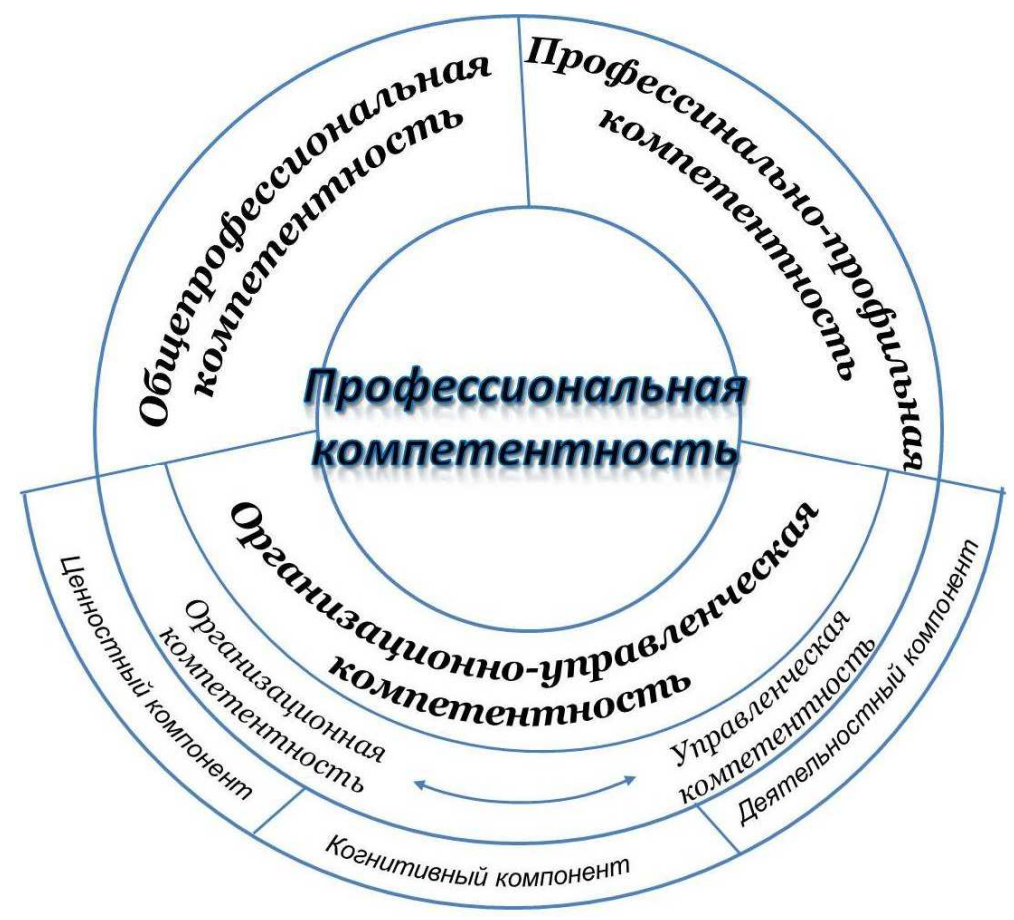

Рисунок 1 - Структура профессиональной компетентности

В структуре профессиональной компетентности, представленной на рисунке 1 , мы выделяем 3 компонента организационно-управленческой компетентности: ценностный, когнитивный и технологический, формирование которых происходит за пять этапов:

- на начальном этапе осознанная потребность инженеров в развитии ОУК формирует мотив познавательной деятельности, начинает формироваться ценностный компонент;

- на оценочно-адаптивном этапе происходит оценка начального уровня ОУК у инженеров, происходит отбор учебных модулей, развивается ценностный компонент;

- на познавательном этапе происходит накопление организационных и управленческих знаний, на основании которых формируются организационные и управленческие умения, формируется когнитивный компонент и начинает формироваться технологический компонент организационно-управленческой компетентности;

- на рефлексивном этапе происходит переосмысление и оценка инженерами полученных знаний, формируются стремления удовлетворять свои 
познавательные потребности и интересы путем самообразовательной деятельности, продолжается развитие когнитивного компонента;

- на деятельностном этапе происходит актуализация результатов обучения, слушатели начинают применять приобретенные знания и навыки в практической деятельности, они осознают собственные способности и возможности при условии непрерывного самообразования в профессиональной сфере, развивается технологический компонент.

Инструментарий для исследования развития компонентов организационноуправленческой компетентности в процессе повышения квалификации представлен в таблице 1.

Таблица 1 - Диагностика развития ОУК инженеров

\begin{tabular}{|c|c|c|c|}
\hline Компоненты & Критерии & Показатели & $\begin{array}{ll}\text { Средства } & \text { и } \\
\text { методы } & \\
\text { диагностики }\end{array}$ \\
\hline Ценностный & Ценности & $\begin{array}{lr}\text { Человекоцентрированные } & \text { ценностные } \\
\text { ориентации; уважение и осознание } \\
\text { значимости других людей; стремление к } \\
\text { успеху; потребность в постоянном } \\
\text { пополнении } \\
\text { самосовершенствовании }\end{array}$ & $\begin{array}{l}\text { тест Т. Элерса } \\
\text { (мотивация к } \\
\text { успеху); } \\
\text { тест Д. Марлоу, } \\
\text { Д. Краун; }\end{array}$ \\
\hline Когнитивный & $\begin{array}{l}\text { Организац } \\
\text { ионные и } \\
\text { управленче } \\
\text { ские } \\
\text { знания }\end{array}$ & $\begin{array}{l}\text { Знания о } \\
\text { организационной } \\
\text { коммуникаций; знания о распределении } \\
\text { полномочий, их делегировании; знания } \\
\text { об организации групповой работы; } \\
\text { знания основ управления организацией } \\
\text { и персоналом; готовность к проявлению } \\
\text { личной } \\
\text { профессиональному инициативы, } \\
\text { управлению людьм косту, } \\
\text { процессами }\end{array}$ & $\begin{array}{l}\text { опросник } \\
\text { «якорь } \\
\text { карьеры» } \\
\text { Шейна; } \\
\text { разработанный } \\
\text { тест }\end{array}$ \\
\hline $\begin{array}{l}\text { Технологичес } \\
\text { кий }\end{array}$ & $\begin{array}{l}\text { Организац } \\
\text { ионные и } \\
\text { управленче } \\
\text { ские } \\
\text { умения }\end{array}$ & 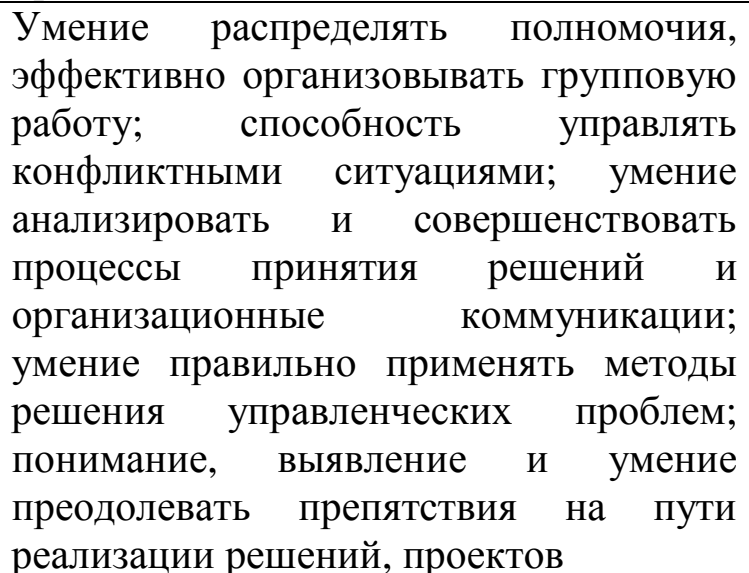 & $\begin{array}{l}\text { наблюдение; } \\
\text { анализ } \\
\text { результатов } \\
\text { работ; метод } \\
\text { самооценки }\end{array}$ \\
\hline
\end{tabular}

Для оценки развития ценностного компонента организационно-управленческой компетентности инженеров были применены методики Т. Элерса (мотивация к успеху 
и мотивация избегания неудач) и Д. Марлоу и Д. Крауна («шкала лжи», стремление к одобрению).

Мотивация стремления к успеху носит положительный характер. При такой мотивации действия человека направлены на достижение конструктивных, положительных результатов. В этом случае личностная активность зависит от потребности в достижении успеха. Мотивация боязни неудачи носит негативный характер. При таком типе мотивации человек стремится прежде всего избежать плохого отношения к себе, и даже наказания. Ожидание неприятностей определяет его деятельность. В этом случае, думая о предстоящей деятельности, человек уже боится возможного провала и ищет выход, как его избежать, а не как добиться успеха. То есть для активации познавательной деятельности слушателей преподавателю нужно актуализировать потребность инженеров в достижении успеха как в процессе обучения в ИПК, так и при последующем решении организационно-управленческих задач в своей профессиональной деятельности [1 - 11].

Для оценки когнитивного компонента применен разработанный тест, количество набранных баллов по которому соответствует количеству данных правильных ответов, а также методика Э. Шейна, позволяющая оценить карьерные ориентации. Среди карьерных ориентаций наибольший интерес представляют ориентации «менеджмент», «профессиональная компетентность», «вызов» и «предпринимательство». Ориентация «профессиональная компетентность» связана с наличием способностей и талантов в определенной области. Люди с такой ориентацией хотят быть мастерами своего дела, они бывают особенно счастливы, когда достигают успеха в профессиональной сфере, но быстро теряют интерес к работе, которая не позволяет развивать их способности. Вряд ли их заинтересует даже значительно более высокая должность, если она не связана с их профессиональными компетенциями. Они готовы управлять другими в пределах своей компетенции, но управление не представляет для них особого интереса. Поэтому многие из этой категории отвергают работу руководителя, управление рассматривают как необходимое условие для продвижения в своей профессиональной сфере. Для людей с якорем карьеры «менеджмент» первостепенное значение имеет ориентация личности на интеграцию усилий других людей, полнота ответственности за конечный результат и соединение различных функций организации. С возрастом и опытом эта карьерная ориентация проявляется сильнее. Возможности для лидерства, высокого дохода, повышенных уровней ответственности и вклад в успех своей организации являются ключевыми ценностями и мотивами. Самое главное для них управление: людьми, проектами, любыми бизнес-процессами - это в целом не имеет принципиального значения. Центральное понятие их профессионального развития власть, осознание того, что от них зависит принятие ключевых решений. Причем для них не является принципиальным управление собственным проектом или целым бизнесом, скорее наоборот, они в большей степени ориентированы на построение карьеры в наемном менеджменте, но при условии, что им будут делегированы значительные полномочия. Человек с такой ориентацией будет считать, что не достиг цели своей карьеры, пока не займет должность, на которой будет управлять 
различными сторонами деятельности предприятия. Люди с ориентацией «вызов» считают успехом преодоление непреодолимых препятствий, решение неразрешимых проблем или просто выигрыш. Они ориентированы на то, чтобы «бросать вызов». Для одних людей вызов представляет более трудная работа, для других это - конкуренция и межличностные отношения. Они чувствуют себя преуспевающими только тогда, когда постоянно вовлечены в решение трудных проблем или в ситуацию соревнования. Карьера для них - это постоянный вызов их профессионализму, и они всегда готовы его принять. Новизна, разнообразие и вызов имеют для них очень большую ценность, и, если все идет слишком просто, им становиться скучно. Людям с ориентацией «предпринимательство» нравится создавать новые организации, товары или услуги, которые могут быть отождествлены с их усилиями. Они не склонны работать на других, являясь предпринимателями по духу, и цель их карьеры - создать что-то новое, организовать свое дело, воплотить в жизнь идею, всецело принадлежащую только им. Вершина карьеры в их понимании - собственный бизнес.

Для изучения технологического компонента, как до повышения квалификации, так и после, нами был выбран метод самооценки, поскольку преподаватели за столь короткий срок, который инженеры проводят в ИПК, не могут в полной мере оценить уровень их организационно-управленческих умений, и для работодателя также не будет мгновенно очевиден результат обучения. Самому же инженеру легче оценить свои умения и навыки.

Для оценки были выделены следующие организационно-управленческие умения:

- формулировать и отдавать распоряжения;

- оценивать эффективность принимаемых решений;

- предвосхищать, констатировать, регулировать и разрешать межличностные конфликты;

- вести переговоры, устанавливать деловые контакты;

- выстраивать иерархию целей организации и определять необходимые для ее достижения ресурсы;

- coхранять способность к эффективной деятельности в сложных и критических ситуациях;

- организовать себя и коллектив для решения задач;

- работать в команде;

- управлять действиями других людей, учитывая способности, возможности и мотивацию сотрудников;

- организовывать и управлять своим временем;

- готовность участвовать в реализации программы организационных изменений;

- способность преодолевать локальное сопротивление изменениям;

- способность оценивать условия и последствия принимаемых организационноуправленческих решений;

- осуществлять поиск, анализ и оценку информации для подготовки и принятия управленческих решений; 
- убедительно аргументировать свою позицию;

- выступать перед аудиторией;

- вести дискуссию и диалог.

Для оценки эффективности разработанной программы повышения квалификации на основе приведенного инструментария предлагается использовать нейросетевой алгоритм многомерной кластеризации - самоорганизующиеся карты Кохонена. Данный выбор обусловлен двумя причинами. Первая заключается в необходимости разработки интегрированного показателя оценки эффективности программы повышения квалификации на основе 9 выделенных тестов. В качестве того показателя может служит «попадание» человека, в один из построенных с помощью данного метода, кластеров. Вторая причина обусловлена обширными возможностями визуализации результатов применения данного метода.

В исследовании приняли участие 115 слушателей программ повышения квалификации ИПК МАДИ. С помощью приведенного инструментария была проведена оценка уровня развития компонентов ОУК до и после повышения квалификации.

Моделирование проводилось в среде MatLab с пакетом SOMToolbox 2.0.

Общая структура самоорганизующейся карты Кохонена [1, 2, 12 - 15], фрагмент которой представлен на рисунке 2 , состоит из 9 нейронов распределительного слоя и 54 нейронных элементов второго слоя, распределенных на сетке 9 на 6 элементов.

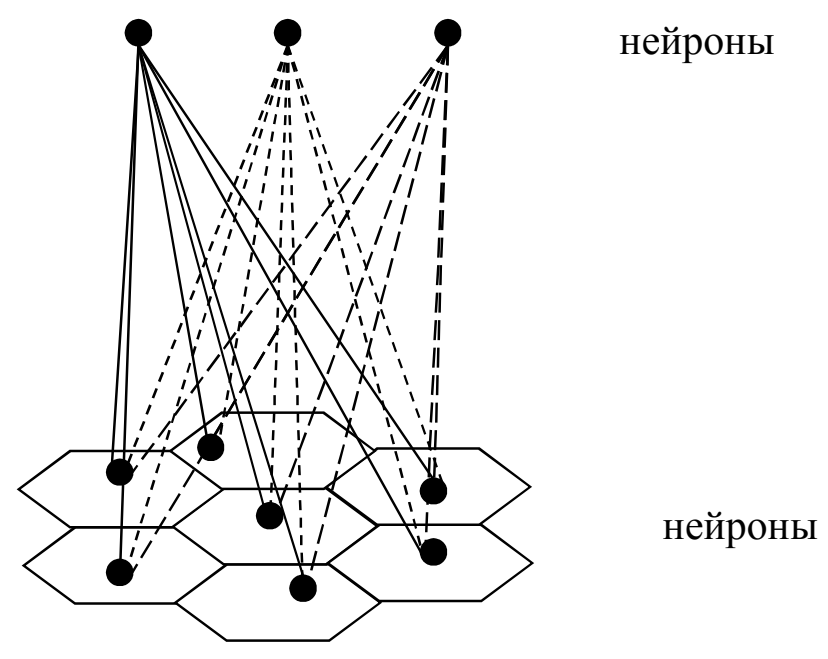

\section{Рисунок 2 - Структура сети Кохонена}

После подачи на сформированную таким образом сеть результатов тестирования 115 респондентов, были получены результаты, анализ которых позволяет сделать следующие выводы:

Всех респондентов можно разделить на три кластера в зависимости от уровня развития ОУК. На рисунке 3 представлена цветовая кодировка матрицы расстояний между элементами самоорганизующейся сети Кохонена, согласно которой, чем ближе нейронные элементы второго слоя сети друг к другу, тем более синим помечается соответствующая ячейка, и наоборот, чем топологически дальше элементы друг от друга, тем более красным кодируется соответствующий элемент. 


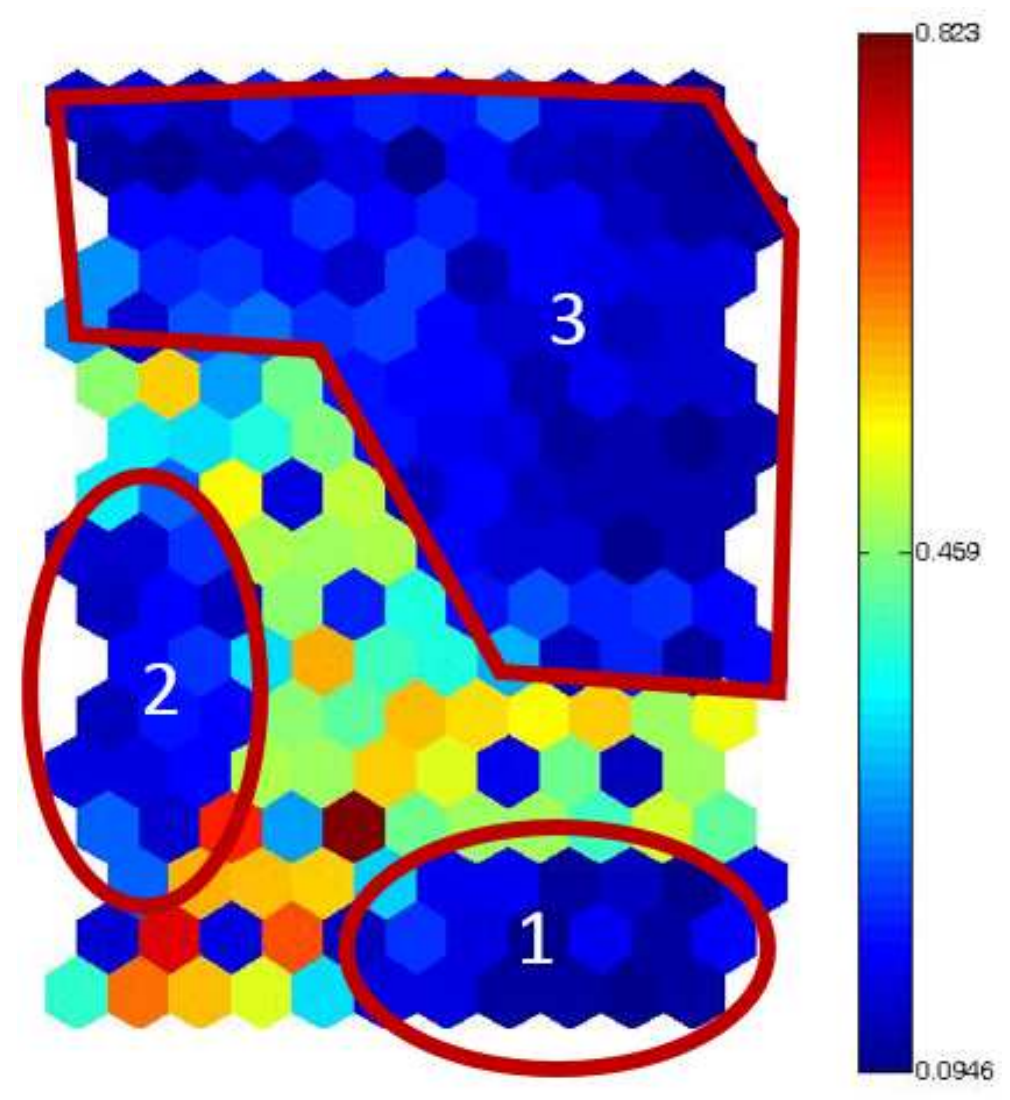

\section{Рисунок 3 - Цветовая кодировка матрицы расстояний между элементами самоорганизующейся сети Кохонена, обученной на основе данных 115 респондентов до повышения квалификации}

Анализ частоты «попаданий» различных респондентов в те или иные нейронные элементы второго слоя рассматриваемой самоорганизующейся сети (рис. 5) показывает, что в первый кластер попадает 20 человек (17\%), во второй 17 человек $(15 \%)$ и в третий, соответственно, 78 человек $(68 \%)$.

После подачи на сформированную карту данных, характеризующих эксперта (на рисунке 4 экспертные данные обозначены ромбом) можно сделать вывод, что уровень организационно-управленческих компетенций респондентов, попавших в один кластер с экспертом, близок к его уровню.

Уровень остальных респондентов существенно ниже экспертного и нуждается в повышении.

На основании результатов входного тестирования слушателям предоставляются рекомендации относительно их индивидуальной программы обучения, показывается, на какие модули программы следует обратить более пристальное внимание.

После освоения программы повышения квалификации, было проведено повторное исследование респондентов по той же методике, которое позволило сделать следующие выводы: 


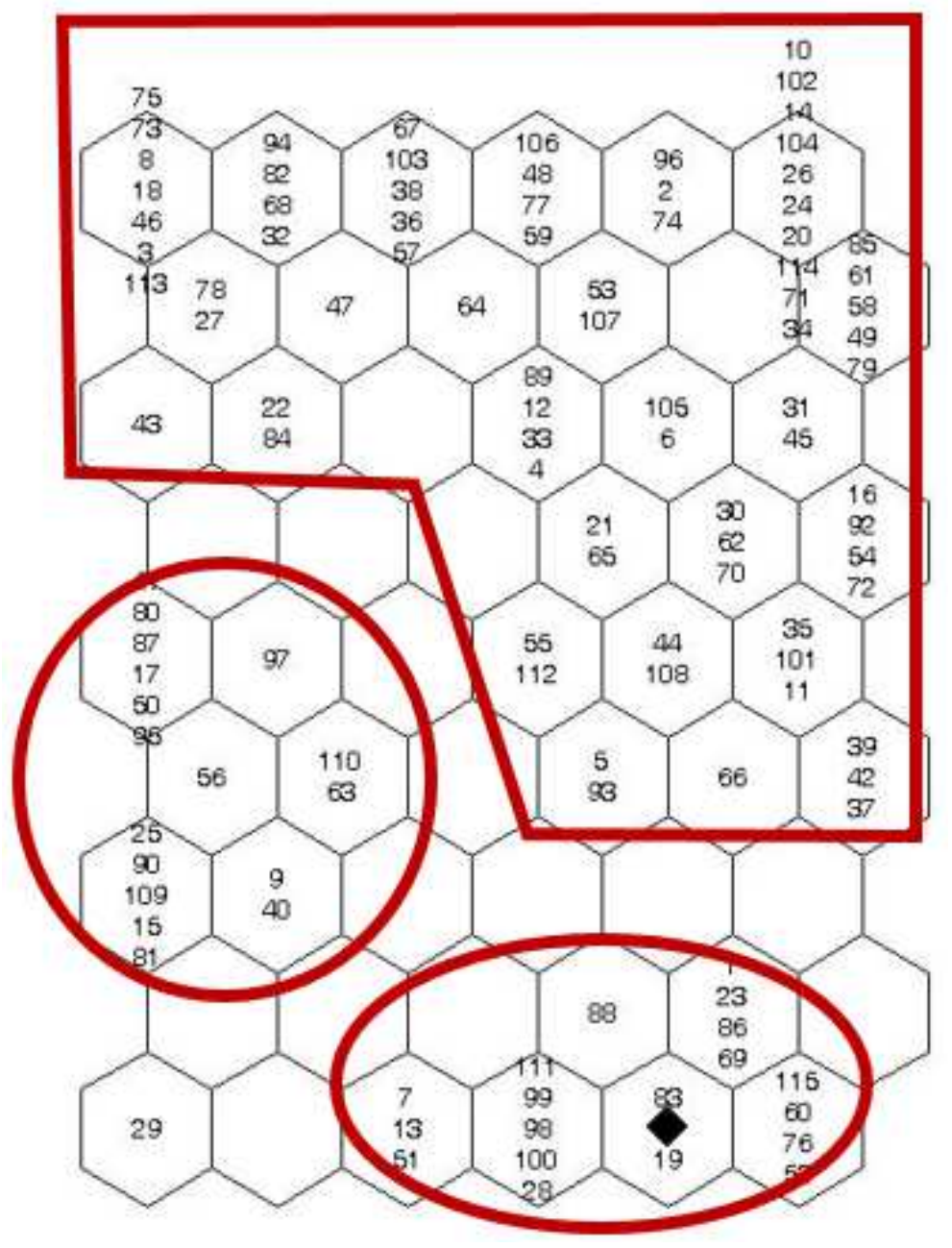

Рисунок 4 - Нейроны самоорганиующейся сети Кохонена, обученной на основе данных 115 респондентов до повышения квалификации

Bcex респондентов можно разделить на три кластера в зависимости от уровня развития ОУК. На рисунке 5 представлена цветовая кодировка матрицы расстояний между элементами самоорганизующейся сети Кохоннена, т.е. чем ближе нейронные элементы второго слоя сети друг к другу, тем более синим помечается соответствующая ячейка, и наоборот, чем топологически дальше элементы друг от друга, тем более красным кодируется соответствующий элемент. 


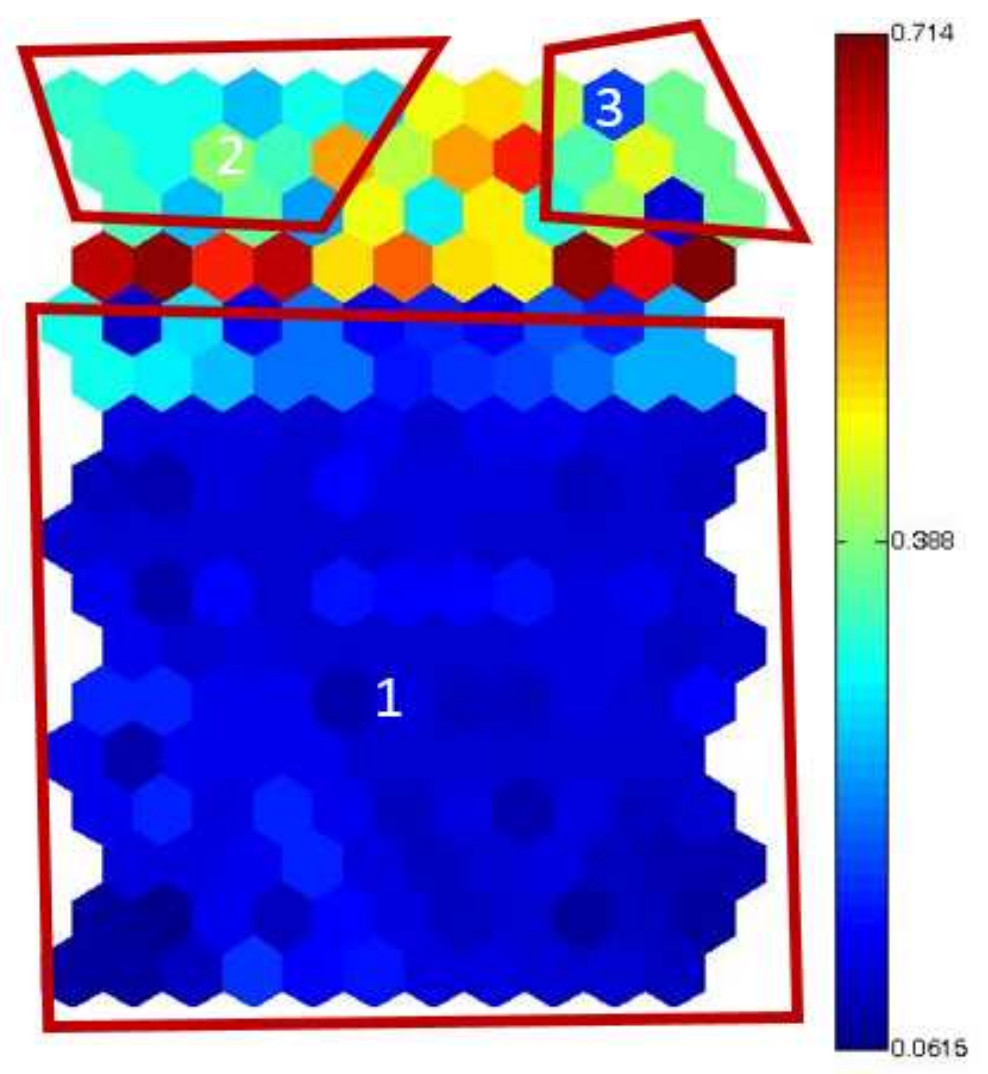

\section{Рисунок 5 - Цветовая кодировка матрицы расстояний между элементами самоорганизующейся сети Кохонена, обученной на основе данных 115 респондентов после повышения квалификации}

Анализ частоты «попаданий» различных респондентов в те или иные нейронные элементы второго слоя рассматриваемой самоорганизующейся сети (рис. 7) показывает, что в первый кластер попадает 99 человек (86\%), во второй - 9 человек (8\%) и в третий -7 человек (6\%).

После подачи на сформированную карту данных, характеризующих эксперта (на рисунке 6 экспертные данные обозначены ромбом) можно сделать вывод, что уровень организационно-управленческих компетенций респондентов, попавших в один кластер с экспертом, близок к его уровню.

Размер кластера, соответствующего уровню развития ОУК «близкого к экспертному» существенно вырос после повышения квалификации (на 69\%).

Полученные результаты позволяют сделать вывод, что положительная динамика получена под влиянием целенаправленного педагогического воздействия, и подтверждают гипотезу о том, что развитие организационно-управленческих компетенций инженеров в процессе повышения квалификации протекает эффективно, если этот процесс осуществляется на основе разработанной структурнофункциональной модели, отражающей комплекс педагогических условий. 


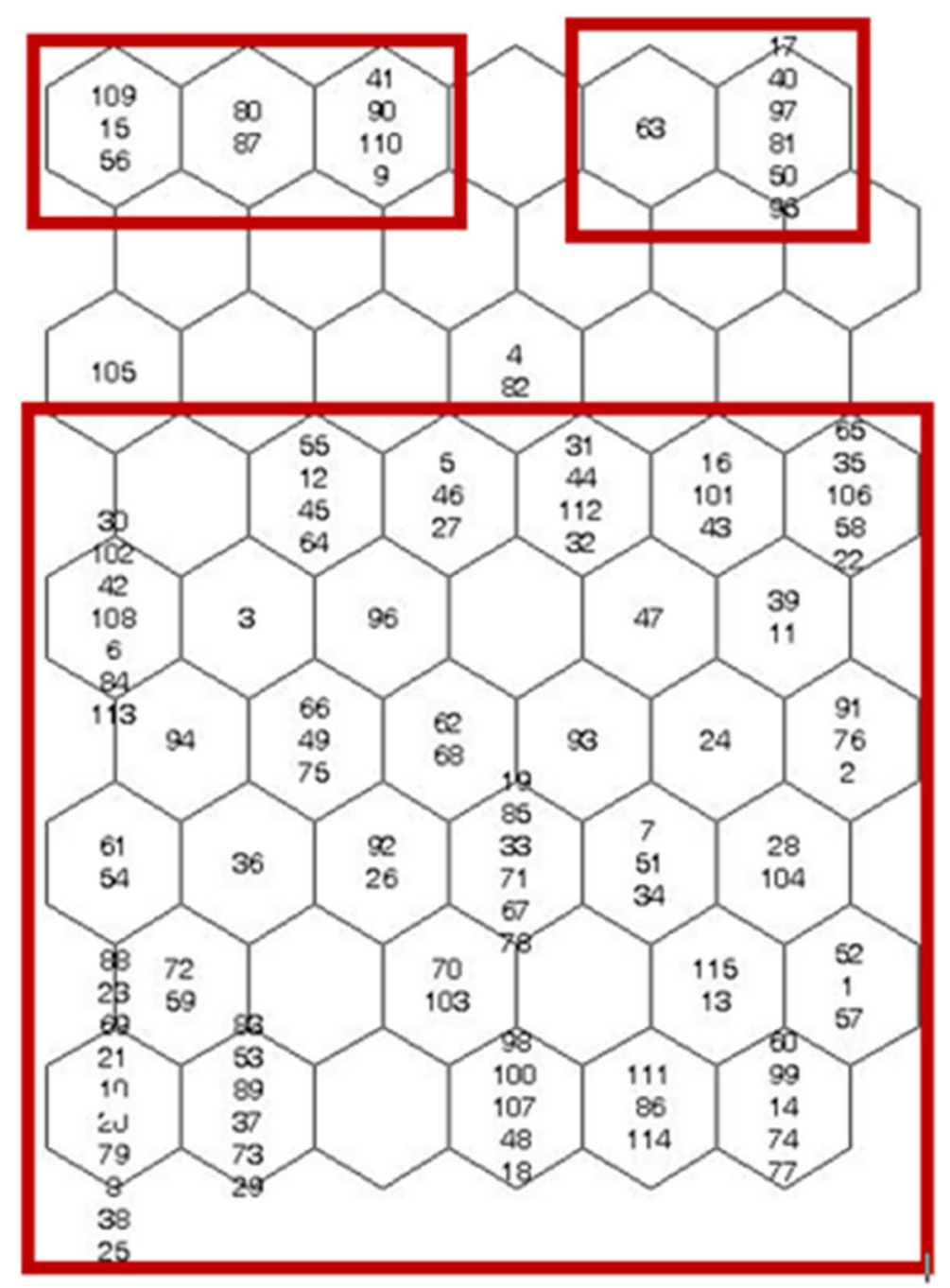

Рисунок 6 - Нейроны самоорганизующейся сети Кохонена, обученной на основе данных 115 респондентов после повышения квалификации

\section{Список информационных источников}

[1] Ахтеров А.В. Выделение геологических неоднородностей нефтегазоносных пластов с применением метода самоорганизующихся нейронных сетей // Автоматизация и управление в технических системах, 2012. №1. С. 76-81.

[2] Ахтеров А.В. Алгоритм самоорганизации распределенных систем // В мире научных открытий. 2012. № 2.6 (26). С. 82-86.

[3] Ахтеров А.В., Лезина О.В., Федоров И.В. Информационно-аналитическая образовательная платформа вуза для интеграции учебного процесса в области менеджмента // В мире научных открытий. 2012. № 2.6 (26). С. 144-158.

[4] Ахтеров А.В. Использование метода самоорганизующихся нейронных сетей для выделения геологических неоднородностей нефтегазоносных пластов // В мире научных открытий. 2012. № 12 (36). С. 32-41.

[5] Ахтеров А.В., Лезина О.В., Федоров И.В. Системная модель информационнообразовательной среды выпускающей кафедры вуза // Вестник Московского 
автомобильно-дорожного государственного технического университета (МАДИ). 2010. № 1. C. 12a-17.

[6] Шастина А.Е. Потребность современного инженера в развитии организационноуправленческих компетенций // Теория и практика общественного развития. 2013. № 6. C. 101-104.

[7] Шастина А.Е. Эмоциональный интеллект как фактор эффективности работы руководителя // В мире научных открытий. 2012. № 12 (36). С. 197-203.

[8] Шастина А.Е., Чувашова А.А. Анализ работы кадровой службы при проведении организационных изменений и разработка рекомендаций по ее совершенствованию (на примере компании ОАО «ЛАЗЕРСЕРВИС») // Молодой ученый. 2011. № 4-3. С. 87-94.

[9] Вражнова М.Н., Шастина А.Е. Особенности формирования управленческих компетенций инженерно-технических специалистов // Казанская наука. 2013. № 3. С. 187-192.

[10] Федоров И.В., Ипполитова Г.К., Минина О.Г., Лезина О.В. Инженерное образование в современном мире // Аккредитация в образовании. 2009. № 34. С. 50.

[11] Лезина О.В. Управление знаниями студентов на выпускающей кафедре вуза // Известия Балтийской государственной академии рыбопромыслового флота: психолого-педагогические науки. 2011. № 1. С. 46-55.

[12] Васюгова С.А. Исследование перспектив и проблем интеграции человека с компьютером: искусственный интеллект, робототехника, технологическая сингулярность и виртуальная реальность / А.В. Остроух, С.А. Васюгова, М.Н. Краснянский, А. Самаратунга // Перспективы науки. - 2011. - № 4(19). - С. 109 112.

[13] Остроух А.В. Основы построения систем искусственного интеллекта для промышленных и строительных предприятий: монография / А.В. Остроух. - М.: OОО «Техполиграфцентр», 2008. - 280 с. - ISBN 978-5-94385-033-2.

[14] Остроух А.В. Системы искусственного интеллекта в промышленности, робототехнике и транспортном комплексе: монография / А.В. Остроух Красноярск: Научно-инновационный центр, 2013. - 326 с. - ISBN 978-5-90631410-9.

[15] Остроух А.В. Информационные технологии в научной и производственной деятельности / [ред. А.В. Остроух] - М: ООО "Техполиграфцентр", 2011. - 240 с. ISBN 978-5-94385-056-1. 